\title{
Fisiopatología elemental, un punto de vista práctico
}

Claudia Cárdenas Demay*

claucar@accessnet.com.mx

Gilberto Quiñones P.

Trillas, 2006

Es un libro planteado para estudiantes de la carrera de Químico-farmacobiólogo y áreas afines, con el afán de hacer un texto más accesible con la información necesaria para ellos. El libro cuenta con tres unidades.

La unidad I (gastropatías) habla de esofagitis, acalasia y estenosis esofágica, además de gastroenteritis, gastritis y úlceras gastrointestinales.

La unidad II (neoplasias) nos habla de los tumores malignos más frecuentes que son cáncer de páncreas, cervicouterino, de mama y de próstata.

La unidad III (enfermedades crónicas) plantea tres trastornos que son muy usuales: enfermedades cardiovasculares, diabetes y obesidad.

En todos los casos se presentan primero generalidades anatómicas y fisiológicas de los órganos en cuestión y después se hace un breve resumen de las patologías estudiadas incluyendo etiología, síntomas, diagnóstico, complicaciones y tratamiento; todo a modo sintético e ilustrado con esquemas. Lo sintético del libro puede considerarse como una fortaleza o una debilidad en función de la profundidad con la que se desee que los alumnos revisen estos temas. 